\title{
Protein Synthesis Directed by an $\mathrm{RNA}^{-}$ Temperature-Sensitive Mutant of Sindbis Virus
}

\author{
MARILYNN R. F. WAITE \\ Department of Microbiology, Dartmouth Medical School, Hanover, New Hampshire 03755
}

Received for publication 22 March 1972

\begin{abstract}
The structural proteins of wild-type Sindbis virus were shown to arise by posttranslational cleavage of larger precursors. The proteins synthesized in wildtype infection were compared with those specified by $t s-11$, a temperature-sensitive mutant unable to synthesize viral RNA at the restrictive temperature. $\mathrm{Ab}$ normally large, virus-specific proteins were found in the mutant-infected cells after the shift from $28 \mathrm{C}$ to $41.5 \mathrm{C}$. These large polypeptides were presumably precursors which were cleaved too rapidly to be detected in the wild-type infection. The largest had a molecular weight of 133,000 and was the same size as the apparent precursor detected during infection with a group of Sindbis mutants which could not form nucleocapsids at the nonpermissive temperature. The stability of $t s$-11-specific RNA synthesis, after shift from permissive to restrictive conditions, differed from that in cells infected by wild-type virus, indicating that the virus had a genetic lesion in an enzyme involved in RNA synthesis. This mutation might have caused the precursor to fold incorrectly so that it could not be cleaved. The possibility cannot be excluded, however, that a second lesion in an uncharacterized viral function, such as a protease, was the cause of the accumulation of the precursors.
\end{abstract}

In enteroviral infections, functional viral proteins are formed by the post-translational cleavage of large precursor polypeptides (1). Precursors large enough to be the gene product of the entire viral genome have been detected $(10,12)$. In group A arbovirus infections, the situation is not as clear. Several reports have noted the inability to detect a precursor protein in chick embryo fibroblast (CEF) cells infected with either wild-type Sindbis virus (20) or Semliki Forest virus (9). When Semliki Forest virus was grown in baby hamster kidney cells, however, definite evidence for the existence of precursors was obtained (5). A recent study by Pfefferkorn and Boyle (16) using inhibitors of protease activity has suggested that, in Sindbis infection, a protein the same size as the largest one present under normal conditions may function as a precursor of the viral membrane and capsid proteins.

Evidence for the existence of a still larger, virus-specified polypeptide in Sindbis-infected CEF was found by Strauss et al. (23) and by Scheele and Pfefferkorn (20) who studied proteins made by temperature-sensitive $(t s) \mathrm{mu}$ tants of Sindbis virus. They found that, at the nonpermissive temperature, cells infected with any of the three members of complementation group $\mathrm{C}$ (capsid ${ }^{-}$, or defective in nucleocapsid formation) did not contain capsid protein (molecular weight 30,000 ; reference 24 ). The predominant protein species in these mutant-infected cells had a lower electrophoretic mobility than those seen during normal infection. This polypeptide was presumably a precursor, although its radioactive label did not chase into smaller proteins when the temperature was lowered (20). Since these mutants are capable of synthesizing viral RNA when incubated from the time of infection at the nonpermissive temperature $\left(\mathrm{RNA}^{+}\right)$, the viral RNA-synthesizing enzyme(s) is presumably freed from this precursor.

found among the $\mathrm{RNA}^{-}$mutants which are unable to make virus-specific RNA at the nonpermissive temperature. A mutation which did not permit any virus-specific proteins to be cut from the precursor would probably result in a viral mutant that was phenotypically $\mathrm{RNA}^{-}$, because it seems unlikely that an RNA polymerase would be functional while it was still part of a large polypeptide. Accordingly, I screened 
the proteins made by the $\mathrm{RNA}^{-}$mutants of Sindbis virus before and after the shift from $28 \mathrm{C}$, the permissive temperature, to $41.5 \mathrm{C}$, the nonpermissive temperature. Acrylamide gel electrophoresis (AGE) revealed a variety of normal and abnormal protein patterns. The most conspicuous of these was that of $t s-11$; after a three-hour labeling period, about $60 \%$ of the virus-specific proteins had electrophoretic mobilities less than that of the membrane protein. In cells infected with the wild-type virus, less than $25 \%$ of the viral protein was this large. The predominant species in the mutantinfected cells was larger than any seen during normal infections. $T s-11$ was, therefore, chosen as the subject for more intensive study. A preliminary report of this work has already appeared (M. R. F. Waite and E. R. Pfefferkorn, Bacteriol. Proc., p. 233, 1971).

\section{MATERIALS AND METHODS}

The isolation and characterization of the $t s \mathrm{mu}$ tants of Sindbis virus and the HR strain from which they were derived (referred to as wild-type), as well as the conditions for their growth and titration, have been described (2-4, 17). After infection, CEF cultures were incubated in Eagle medium containing $3 \%$ rabbit serum and actinomycin D $(1 \mu \mathrm{g} / \mathrm{ml})$. To deplete the amino acid pools of cultures being prepared for AGE, the medium was modified to contain only $1 \mu \mathrm{g}$ of leucine per $\mathrm{ml}$ (low leucine medium) or one-tenth the normal amount of amino acids (low amino acid medium). Radioactive precursors, obtained from Schwartz BioResearch, Inc., included ${ }^{3} \mathrm{H}$-leucine $(40 \mathrm{Ci} / \mathrm{mmole})$, reconstituted ${ }^{14} \mathrm{C}$-protein hydrolysate $(500 \mu \mathrm{Ci} / \mathrm{ml})$, and ${ }^{3} \mathrm{H}$-uridine $(25$ $\mathrm{mCi} / \mathrm{mmole})$. Chase medium contained an excess of unlabeled leucine $(100 \mu \mathrm{g} / \mathrm{ml})$.

To examine virus-specific RNA, infected cells were preincubated with actinomycin $D$, labeled with ${ }^{3} \mathrm{H}$-uridine, and treated as described previously (4). Briefly, the labeled monolayers were washed and dissolved in a buffered solution containing sodium dodecyl sulfate (SDS) and ethylenediaminetetraacetate. Portions of the cell extracts were analyzed on 15 to $30 \%$ SDS-glycerol gradients (12).

The procedures for preparing extracts of labeled cells and subjecting them to AGE were identical to those employed by Scheele and Pfefferkorn (18), except that $7.5 \%$ polyacrylamide gels were employed. Samples of from 0.05 to $0.2 \mathrm{ml}(5,000$ to 70,000 counts/min of ${ }^{3} \mathrm{H}$ or 1,000 to 2,000 counts/min of ${ }^{14} \mathrm{C}$ ) were applied to the gels. Unless otherwise specified, a $0.05-\mathrm{ml}$ sample of an extract of purified Sindbis virus labeled with ${ }^{14} \mathrm{C}$-protein hydrolysate was coelectrophoresed with each sample to indicate the location of the viral membrane and capsid proteins.

To determine the molecular weights of the large proteins, their electrophoretic mobility was compared with that of thyroglobulin (molecular weight 160,000; reference 26) and bovine serum albumin (BSA) (molecular weight 67,000 ). The thyroglobulin preparation contained traces of two minor protein species, one slightly larger and one slightly smaller than thyroglobulin. When boiled prior to electrophoresis, the BSA preparation gave only a single band. If unboiled, a pronounced band with a molecular weight of 134,000 , presumably the dimer, was also observed; this was used as an additional marker. ${ }^{3} \mathrm{H}$-labeled $t s$-11-specific viral protein or ${ }^{14} \mathrm{C}$-labeled $t s$-13-specific protein were mixed with one or both markers and subjected to AGE on 5 or $7.5 \%$ gels at $5 \mathrm{~mA} / \mathrm{gel}$ until the bromophenol blue marker neared the bottom of the tube. The gels were stained with Coomassie blue in methanol-acetic acid for two $\mathrm{hr}$ and destained by soaking for two days in several changes of the methanol-acetic acid solution (26). The gels were then soaked overnight in $7.5 \%$ acetic acid, and the locations of the stained bands were determined. The gels were frozen and sliced with a transverse gel slicer (Misco Scientific). After soaking overnight in NCStoluene scintillation fluid (Amersham/Searle). the slices were counted to determine the locations of the radioactive peaks. The relative mobilities and molecular weights were determined as described by Weber and Osborn (26).

\section{RESULTS}

Protein synthesis directed by wild-type Sindbis. The permissive temperature, at which the $t s$ mutants of Sindbis virus grow well, is 28 C. Since the previous studies of protein synthesis directed by wild-type arboviruses have been carried out at $37 \mathrm{C}(5,9,20,23)$, it seemed advisable to reexamine the pattern of protein synthesis by wild-type Sindbis virus at $28 \mathrm{C}$ to provide a basis for comparison with the mutantinfected cells. Replicate CEF cultures were infected and incubated at $28 \mathrm{C}$ for $8 \mathrm{hr}$ in low leucine medium. They were then exposed for two min to medium containing ${ }^{3} \mathrm{H}$-leucine. One culture was processed immediately, whereas the other was washed and incubated for an additional $30 \mathrm{~min}$ in chase medium to allow the labeled proteins to be converted into their final form. The chased culture contained $10 \%$ less radioactive protein than the culture dissolved immediately after labeling, confirming the effectiveness of the chase conditions. Both preparations were subjected to AGE, and a comparison of the two patterns appears in Fig. 1.

After the 2-min pulse, the membrane (M) and capsid (C) protein peaks were present, although much reduced in comparison with experiments performed at $37 \mathrm{C}(20,23)$ or from the 30 -min chase at $28 \mathrm{C} \mathrm{(Fig.} \mathrm{1).} \mathrm{Although} \mathrm{no}$ proteins with very high molecular weights were observed, there was increased label in the region of the large protein $(\mathrm{L}$; moelcular weight 90,000 to 10,000 ; reference 23 ) and a signifi- 


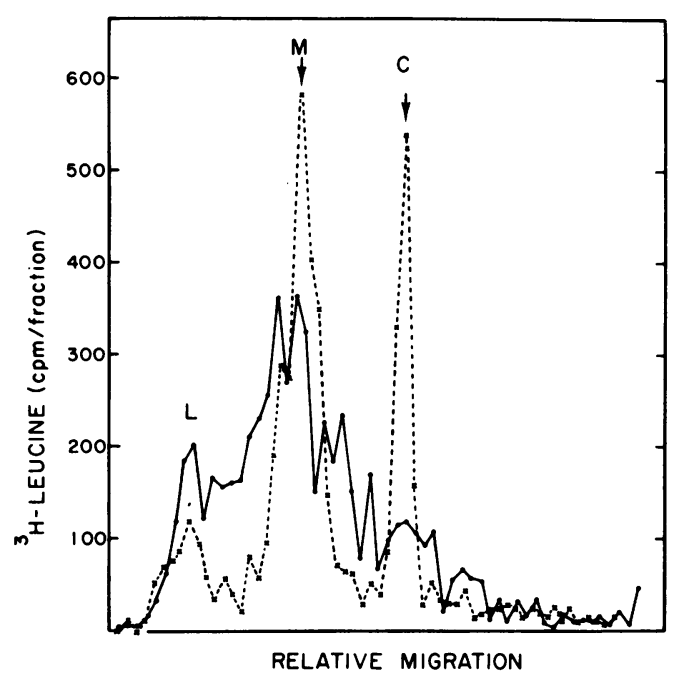

Fig. 1. Pulse-chase experiment with the protein of the wild-type virus at $28 \mathrm{C}$. Cultures infected with the wild-type virus were incubated at $28 \mathrm{C}$ for $8.5 \mathrm{hr}$ in low-leucine medium. They were then washed and exposed for 2 min to medium containing ${ }^{3} \mathrm{H}$-leucine $(100 \mu \mathrm{Ci} / \mathrm{ml})$ and no additional unlabeled leucine. One culture (-) was prepared immediately for $A G E$. The other was washed, and exposed for $30 \mathrm{~min}$ to chase medium, and then processed (-- ). The graphs were then plotted so that the capsid protein markers of both preparations were superimposed. The letters $M$ and $C$ in this and subsequent figures indicate the positions of the membrane and capsid protein from the virus marker. The letter $L$ indicates the location of the large protein normally found in infected cells. Migration was from left to right.

cant amount of material which migrated between the $\mathrm{L}$ protein and the membrane protein. The protein in this region may represent some large molecules in the process of being synthesized, as well as intermediate cleavage products of the precursors. (The role of the protein migrating 2 fractions behind the membrane peak as a precursor to the membrane protein has been described [23]). After the chase, the radioactivity in the $\mathrm{L}$ peak was reduced approximately $25 \%$, and the amount of label migrating between $\mathrm{L}$ and the membrane peak and between the membrane and the capsid peaks decreased markedly. Most of the label chased from these regions appeared in the membrane and capsid peaks. This experiment demonstrates that Sindbis virus structural proteins arise by the post-translational cleavage of larger proteins; it also supports the suggestion from experiments with protease inhibitors (16), that some of the protein in the peak marked L is rapidly cleaved under normal conditions and serves as a precursor to the structural proteins. Lowering the incubation temperature apparently slowed cleavage more than synthesis, allowing the precursor-product relationship among the virus-specified proteins to be discerned. The label which does not chase from the $\mathrm{L}$ peak may represent a different protein species.

Proteins synthesized during infection with ts-11. Figure 2 illustrates typical patterns of protein synthesis in $t s$-11-infected CEF under various conditions. The electropherograms on the left-hand side of Fig. $2(\mathrm{~A}-\mathrm{C})$ were obtained from cultures that were infected with $t s-11$, incubated for $8 \mathrm{hr}$ at $28 \mathrm{C}$, and then labeled with ${ }^{3} \mathrm{H}$-leucine at that temperature. Parts A and B show 2-min and 1-hr pulses, respectively. The patterns are similar to those obtained during infection with wild-type virus under the same conditions. This is not surprising since the mutant grows well at $28 \mathrm{C}$ and would be expected to produce normal, or nearly normal, proteins. There was no indication of a very high-molecular-weight precursor.

Panel C shows the effect of a 1-hr chase at $28 \mathrm{C}$, in medium containing an excess of unlabeled leucine, on a culture infected, incubated, and labeled as in panel B. There was no sign of any further chase. The high-molecular-weight peak (C: fractions 11 to 17 ) is lower, but it is also broader and contains approximately the same proportion of the label as the corresponding peak in panel $\mathrm{B}$ (fractions 11 to 14).

$\mathrm{RNA}^{-}$mutants are unable to make detectable amounts of virus-specific protein when incubated from the time of infection at the nonpermissive temperature. To examine the pattern of protein synthesis under restrictive conditions, I incubated the infected cultures at $28 \mathrm{C}$ for $8 \mathrm{hr}$, shifted them to $41.5 \mathrm{C}$ when the infection was well established, and labeled them at that temperature by exposure to medium containing ${ }^{3} \mathrm{H}$-leucine. The electrophoretic patterns of proteins made at $41.5 \mathrm{C}(\mathrm{D}-\mathrm{F})$ are strikingly different from those at $28 \mathrm{C}$. The most conspicuous feature of all three profiles is the presence of two large, slowly moving peaks near the origins (left-hand side) of the gels. A third, smaller peak, which was better resolved if the proteins were allowed to migrate further, was also present. These peaks were not artefacts of the high incubation temperature: chase at $41.5 \mathrm{C}$ of cultures labeled at 28 $\mathrm{C}$ did not cause the appearance of proteins with abnormally high molecular weights (unpublished data). 


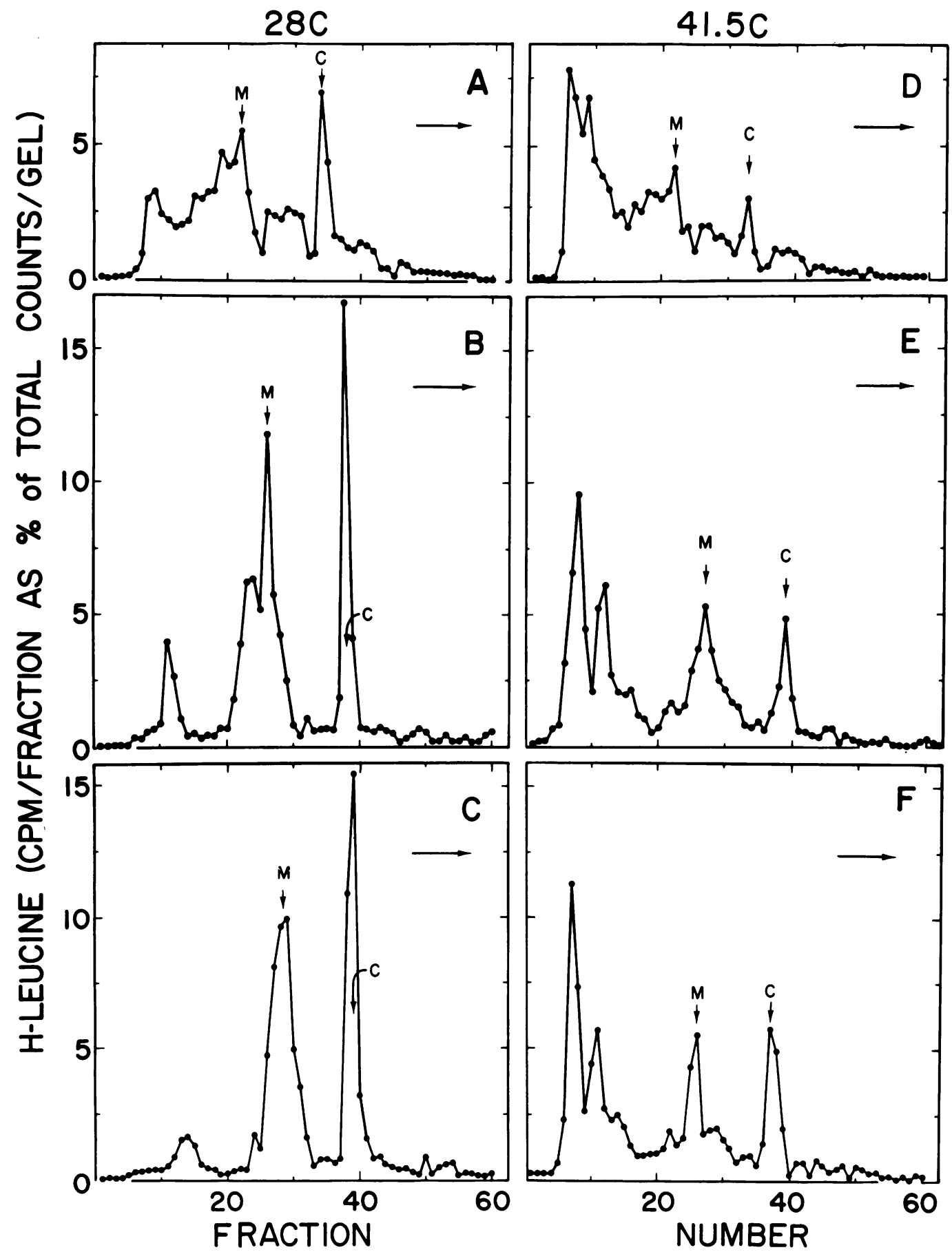

Fig. 2. Ts-11-specific proteins synthesized at $28 \mathrm{C}$ and $41.5 \mathrm{C}$. All cultures were infected with ts-11, incubated at $28 \mathrm{C}$ in low-leucine medium for $8 \mathrm{hr}$, and then treated as follows. (A) The medium was discarded, the culture was washed with Hanks balanced salt solution (BSS), and the bottle was filled with BSS at 28 C and placed in a water bath at that temperature for $3 \mathrm{~min}$. The BSS was discarded, and $1.5 \mathrm{ml}$ of medium containing ${ }^{3} \mathrm{H}$-leucine $(100 \mu \mathrm{Ci} / \mathrm{ml})$ and no unlabeled leucine was added. Incubation was continued for 2 min with the culture submerged in the water bath and rocked continuously. It was processed immediately. (B) An infected culture was treated as in $A$ except that the labeling period was $1 \mathrm{hr}$, the radioactive medium contained $25 \mu \mathrm{Ci}$ of ${ }^{3} \mathrm{H}$-leucine per $\mathrm{ml}$, and the incubation was carried out in an incubator instead of a water bath. (C) $\mathrm{A}$ culture was labeled as in $B$, washed with warm BSS, and incubated for an additional hour in chase medium. The cultures in the right-hand column $(D, E, F)$ were treated exactly like the corresponding culture in the lefthand column $(A, B, C)$ except that the preincubation in BSS and the ${ }^{3} H$-leucine labeling were carried out at 41.5 C. After labeling at $41.5 \mathrm{C}$, the culture shown in $F$ was incubated in chase medium at $28 \mathrm{C}$. 
Panel D shows the profile of the proteins synthesized during a 2-min pulse of ${ }^{3} \mathrm{H}$-leucine. More than $60 \%$ of the tritiated protein present after the 2-min pulse had a molecular weight greater than that of the membrane protein. The membrane and capsid peaks were present but much reduced.

Comparison of panel D with panel E, which shows the pattern obtained after a 1-hr labeling period, reveals that some of the high-molecular-weight protein seen in the 2-min pulse (D: fractions 16 to 22) appeared in the membrane and capsid protein peaks with time. However, the label in the high-molecular-weight peaks (D: fractions 5 to 15 ) was trapped there and did not appear to chase. The three peaks contained about $40 \%$ of the total label after the 2-min pulse, $50 \%$ after a $1-\mathrm{hr}$ exposure to the label, and $60 \%$ after $3 \mathrm{hr}$ (not shown). Panel $\mathrm{F}$ shows the effect of a 1-hr chase at $28 \mathrm{C}$ of a culture infected, incubated, and labeled as was the culture in panel $\mathrm{E}$. There was no alteration of the distribution of radioactivity among the various peaks. Thus, the large $t s$-11-specific proteins, like those of the capsid ${ }^{-}$mutants studied by Scheele and Pfefferkorn (20), did not chase into lower-molecular-weight ones, either at permissive or nonpermissive temperatures.

RNA synthesis in ts-11-infected cells. Although $t s-11$ is phenotypically $\mathrm{RNA}^{-}$and cannot synthesize viral RNA when incubated at the nonpermissive temperature from the time of infection, this does not mean that there is necessarily a mutation in a nucleotide sequence which codes for a protein involved in RNA synthesis.

Any defect which left a protein required for viral RNA synthesis trapped within an uncleaved precursor at the nonpermissive temperature could result in a mutant that was phenotypically $\mathrm{RNA}^{-}$, regardless of whether the lesion was actually in the amino acid sequence required for viral RNA synthesis. A mutation in some other region of the precursor or in a virus-specified protease could have the same effect.

Proteins freed from the precursor during infection with a cleavage-failure mutant at the permissive temperature should be as stable on shift to the restrictive temperature as the corresponding ones made in response to infection with the ancestral wild-type virus, except for the protein containing the $t s$ lesion. This protein might be (but need not be) less stable. All of the functional proteins produced at $28 \mathrm{C}$ might conceivably have the normal, wild-type amino acid sequence if the lesion were in a portion of the precursor polypeptide that was nor- mally excised, as in the proinsulin to insulin conversion (6).

I attempted to localize the defect in $t s-11$ by determining whether the RNA-synthesizing system coded for by $t s-11$ had a different thermal stability from that of the wild-type virus. The rate of $t s-11$ RNA synthesis following the shift from 28 to $41.5 \mathrm{C}$ was examined first. During the first hour after the shift, it increased above the $28 \mathrm{C}$ control which remained essentially constant. However, by the third hour, it had dropped well below control levels. This is significantly different from the reported behavior of the wild-type virus: under similar conditions, the rate of RNA production increased with the increased temperature and did not subsequently decline (19). Other $\mathrm{RNA}^{-}$mutants were affected in various ways by similar temperature-shift-up conditions. Some behaved like the wild-type virus (Scheele and Pfefferkorn, unpublished observation); the rate of RNA synthesis of others declined very rapidly ( $t s-6$, complementation group B) (25), or somewhat more slowly ( $t s-24$, complementation group A) (19), during the first hour after the temperature was raised.

I therefore examined the distribution of ${ }^{3} \mathrm{H}$ uridine label between the $26 s$ and $42 s$ species of $t s$-11-specific, single-stranded RNA under several conditions; the results are shown on the left-hand side of Fig. 3. The pattern of $t s$ 11-specific RNA synthesized between 6 and 7 $\mathrm{hr}$ after infection at $28 \mathrm{C}$ (top panel) was similar to published profiles of the wild-type RNA synthesis $(4,7,19)$. The curve during the first hour after the shift to $41.5 \mathrm{C}$ (middle panel) showed that incorporation had increased slightly at 41.5 C. The profile was similar to that of the control, suggesting the stability of the RNAsynthesizing enzymes for at least $1 \mathrm{hr}$ at $41.5 \mathrm{C}$. Close inspection of the profiles, however, revealed that the ratio of $26 s$ RNA to $42 s$ RNA was altered from approximately 2.3 at $28 \mathrm{C}$ to 1.8 at $41.5 \mathrm{C}$. Between 2 and $3 \mathrm{hr}$ after temperature elevation (bottom panel), this trend had become pronounced. Although the amount of label in the $42 s$ peak actually increased somewhat, the synthesis of $26 s$ RNA was markedly inhibited, giving a $26 s / 42 s$ RNA ratio of 0.6 . A similar effect was observed by Scheele and Pfefferkorn (19) in cells infected with $t s-24$ during the first hour after temperature shift.

Before such a result can be interpreted as demonstrating a defect in a viral RNA-synthesizing enzyme, it is necessary to show that the decline did not result from nonproduction of a required protein, a situation which might have occurred if the protein was trapped within an 


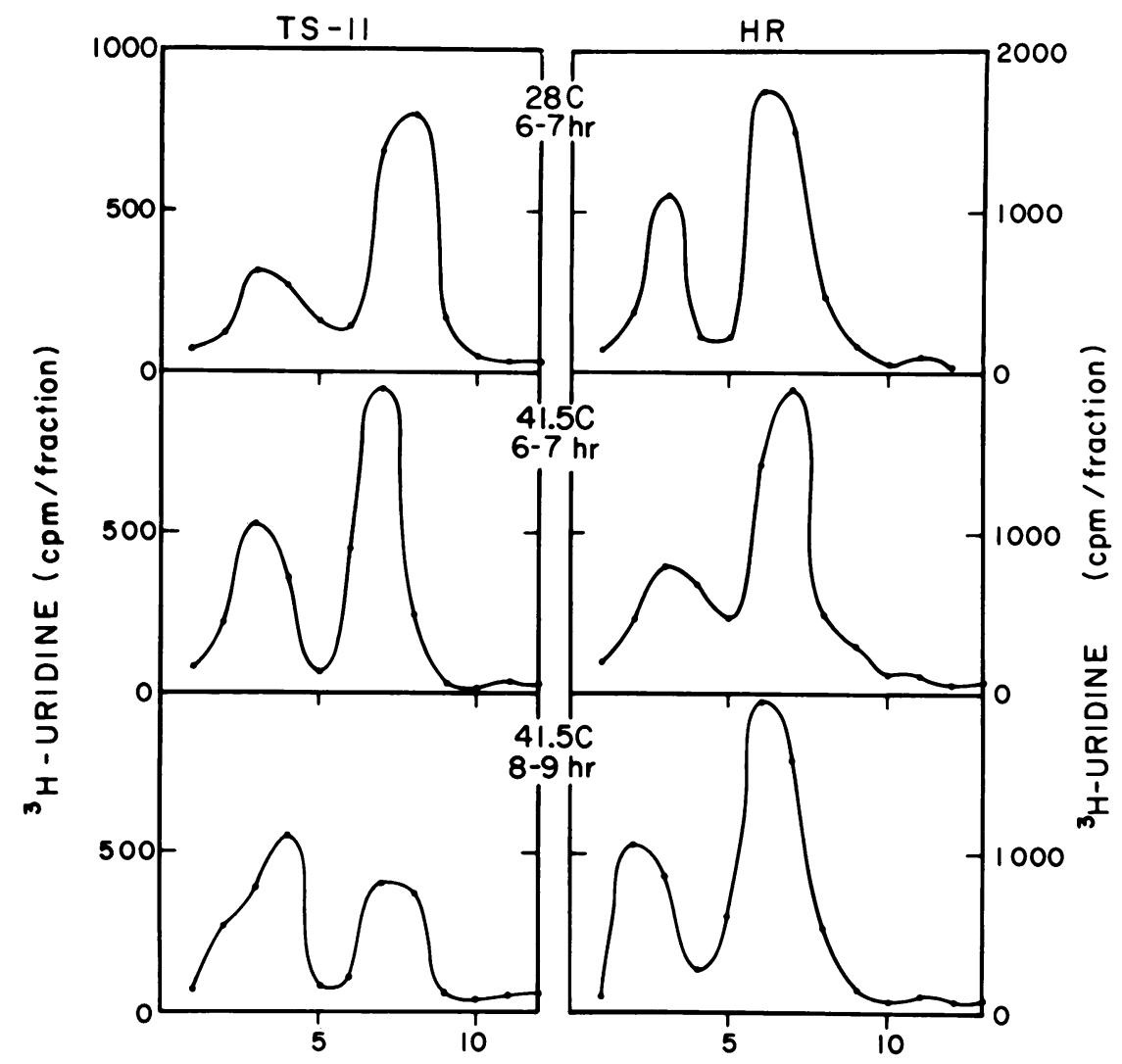

\section{FRACTION NUMBER}

Fig. 3. Distribution of virus-specific RNA between the $26 s$ and $42 s$ single-stranded species under various conditions of incubation. After infection with ts-11 or wild-type virus, replicate cultures were incubated at $28 C$ in the presence of actinomycin $D(1 \mu \mathrm{g} / \mathrm{ml})$. At $6 \mathrm{hr}$ after infection, some cultures were shifted to $41.5 \mathrm{C}$ and cycloheximide $(25 \mu \mathrm{g} / \mathrm{ml})$ was added to the cultures infected with the wild-type virus only. Ts-11 and wildtype-infected cultures at $28 \mathrm{C}$ and at $41.5 \mathrm{C}$ were labeled for $1 \mathrm{hr}$ by exposure to medium containing ${ }^{3} \mathrm{H}$-uridine $(5 \mu \mathrm{Ci} / \mathrm{ml})$ and dissolved in $1 \mathrm{ml}$ of buffered $1 \% \mathrm{SDS}$ solution. Between 8 and $9 \mathrm{hr}$ after infection $(2$ and $3 \mathrm{hr}$ after temperature elevation), an additional mutant-infected culture and one infected with wild-type virus were labeled at $41.5 \mathrm{C}$. (The culture infected with the wild-type virus was maintained in the continuous presence of cycloheximide.) Samples of $0.2 \mathrm{ml}$ of the dissolved cultures were analyzed by ultracentrifugation. Migration was from right to left; $42 s$ RNA is at the left, and $26 s$ is on the right.

uncleaved precursor. The right-hand column shows an experiment using cells, infected with the wild-type virus, which were incubated and shifted like the ts-11-infected cells, but with cycloheximide $(25 \mu \mathrm{g} / \mathrm{ml})$ added at the time of shift to inhibit the subsequent production of new proteins. The ratio of $26 s$ to $42 s$ virusspecific RNA remained normal in cells infected with the wild-type virus, and the amount of viral RNA made did not decline after several hours at $41.5 \mathrm{C}$ in the absence of protein synthesis. Thus, it seems logical to assume that a temperature-sensitive defect in $t s-11$ is in a polypeptide necessary for viral RNA synthesis.
Determination of protein sizes. At the nonpermissive temperature, cells infected with those $t s$-mutants of Sindbis virus which are defective in nucleocapsid formation $(t s-2, t s-5$ and $t s-13)$, and with the RNA- mutant $t s-11$, contained abnormally large proteins $(20)$. To compare the size of the $t s-11$ precursors with those of the capsid- mutants, $t s$-13-specific protein, made at the nonpermissive temperature and labeled with ${ }^{14} \mathrm{C}$-protein hydrolysate, was coelectrophoresed with a sample of $t s-11$ protein labeled at $41.5 \mathrm{C}$ as described in Fig. $2 \mathrm{E}$. The results (Fig. 4) indicate that the large precursor protein specified by $t s-13$ is almost 


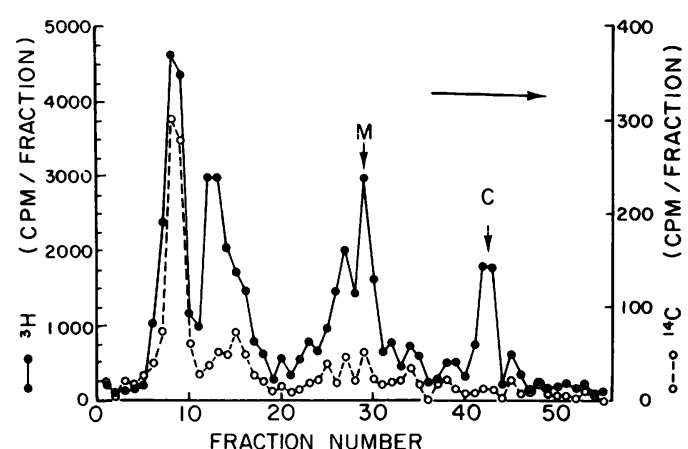

Fig. 4. Coelectrophoresis of the large proteins made during infection by a capsid ${ }^{-}$mutant and by ts-11. A culture infected with ts-13 was incubated for $3.5 \mathrm{hr}$ at $40 \mathrm{C}$ in low amino acid medium. It was then exposed for an additional $3.5 \mathrm{hr}$ to similar medium containing ${ }^{14} \mathrm{C}$ protein hydrolysate $(5 \mu \mathrm{Ci} / \mathrm{ml})$ and prepared for electrophoresis. A 0.1-ml sample of this culture $(\mathrm{O})$ was mixed with a $0.1-\mathrm{ml}$ sample of ${ }^{3} H$-leucine-labeled ts-11-specific protein (O) prepared as that in Fig. $2 E$, and they were subjected to acrylamide gel electrophoresis. No virus protein markers could be included with this experiment; however, the location of the membrane $(M)$ and capsid $(C)$ proteins was known from previous electrophoresis of the ts-11 preparation in the presence of markers.

exactly the same size as the largest protein made during $t s-11$ infection. Similar results were obtained on $5 \%$ gels.

Since Strauss et al. (23) reported that the $t s-13$ precursor had a molecular weight of 130,000 and Scheele and Pfefferkorn (20) reported that the same protein had a molecular weight of approximately 90,000 , it seemed advisable to redetermine the molecular weight. Samples of radioactively labeled preparations of $t s$-11-specific and $t s$-13-specific proteins were coelectrophoresed with unboiled BSA (molecular weight of the monomer 67,000 and that of the dimer 134,000 ) and thyroglobulin (molecular weight 160,000; reference 26). After electrophoresis, the gels were stained with Coomassie brilliant blue to reveal the location of the markers (26) and then sliced with a transverse gel slicer. The slices were counted to determine the location of the radioactive peaks. The molecular weight of the large precursor, determined as described by Weber and Osborn (26), is 133,000 . The molecular weights of the smaller, abnormal, ts-11-specific precursors are approximately 112,000 and 95,000 .

\section{DISCUSSION}

$T s-11$ is a temperature-sensitive mutant of Sindbis virus which is phenotypically RNA $^{-}$; at the nonpermissive temperature, it causes the formation of abnormally large proteins which are presumably nonfunctional precursors or large portions of improperly cleaved precursors. There are three possible explanations for such behavior. (i) An alteration in the amino acid sequence of a protein required for RNA synthesis causes misfolding of the precursor so that it cannot be properly cleaved. (ii) An alteration in some other amino acid sequence changes the conformation of the polypeptide and prevents the release of several proteins, including one required for viral RNA synthesis, which would be functional if released; the mutant would then be phenotypically, but not genotypically, RNA-. (iii) $T s-11$ is a double mutant with a lesion in a protein required for RNA synthesis and a second defect which leads to the production of an uncleaved precursor. This large polypeptide might or might not contain the amino acid sequence for the altered RNA-synthesizing enzyme.

Evidence presented above indicates that the RNA-synthesizing system produced by $t s-11$ during incubation at the permissive temperature is less stable after the shift to the nonpermissive temperature than that of the wild-type virus. This suggests that at least one protein required for viral RNA synthesis has an altered amino acid sequence and that the mutant is genotypically as well as phenotypically $\mathrm{RNA}^{-}$. The possibility that $t s-11$ is a double mutant cannot be eliminated.

The second mutation, if it exists, is not in the membrane or capsid proteins, nor in the unknown function in which $t s-20$ is defective, nor in the RNA-synthesizing protein in which $t s-6$ is defective (17), because the mutant complements efficiently with members of all these groups. If the virus codes for the enzyme causing precursor cleavage, this enzyme could be the site of the second lesion. If so, the postulated abnormal cleavage enzyme is probably not the one responsible for the cleavage of the protein L (Fig. 1). Tosylphenylalanylchloromethyl ketone, which apparently prevents the cleavage of the $L$ protein, does not cause the appearance of the larger proteins seen in $t s$-11-infected cells (16).

At least one $t s$ mutation of $t s-11$ may be in the A cistron, since the late-appearing defect in $t s$ 11 RNA synthesis is similar to that of many of the accepted members of complementation group A (19; Scheele and Pfefferkorn, unpublished data). However, ts-11 behaves in anomalous fashion compared with other members of group A. It was originally assigned to an independent complementation group be- 
cause it complemented somewhat with other $\mathrm{RNA}^{-}$mutants which were placed in group A (3). The discovery of mutant ts-6 (group B), which complements with very high efficiency with all other $\mathrm{RNA}^{-}$mutants, led to a reassignment of $t s-11$ to group A (17). It was subsequently reclassified in a new complementation group $\mathrm{A}^{\prime}$, because of its unique behavior in the intrinsic interference assay of Marcus and Zuckerbraun (15). They found that, unlike members of groups A or B, ts-11 could interfere with Newcastle disease virus replication at the nonpermissive temperature, but only in certain unusual lots of primary African green monkey kidney cells. This led them to believe that the mutant had a $t s$ mutation in a third protein $\left(\mathrm{A}^{\prime}\right)$ required for RNA synthesis and that a viral contaminant of the unusual monkey kidney cells provided this activity, although no Sindbis RNA synthesis was detectable. Ts-11 may indeed have a mutation in a third gene required for viral RNA synthesis; however, it could still be a member of group A. Both the complementation pattern and the unique behavior in the interference assay could result from the failure of precursor cleavage in cells infected by this mutant. The unknown factor which allowed $t s$ 11 to interfere with Newcastle disease virus replication at the nonpermissive temperature could have been a different protease which could cleave the precursor, thus releasing a marginally functional A protein. Alternatively, the presence of a protein similar to A and supplied by the postulated contaminating virus might promote cleavage of the precursor. Leakiness or intracistronic complementation could then explain the interference.

The largest proteins in $t s$-11- and $t s$-13-infected CEF have molecular weights of about 133,000 . Since both $\mathrm{RNA}^{+}$and RNA- mutants cause the production of polypeptides of similar size, it is tempting to postulate that they are identical and might represent the entire polypeptide product of a major messenger RNA species. In a study of the single-stranded RNA species in Sindbis-infected cells, Levin and Friedman (13) found, in addition to $42 s\left(4 \times 10^{8}\right.$ daltons, reference 7$)$ and $26 s\left(1.8 \times 10^{8}\right.$ daltons, reference 7) RNA, three minor species: $38 s$ ( $3.1 \times 10^{6}$ daltons), $33 s\left(2.4 \times 10^{6}\right.$ daltons $)$ and one smaller than the 26s RNA, for which I calculated a molecular weight of $0.6 \times 10^{6}$ to $0.8 \times 10^{6}$. This should have a sedimentation coefficient of about 16s (14). Recent investigations of the RNA species associated with the polysomes of cells infected with group A arboviruses have revealed $33 s$ and $26 s$ RNA (11) or $26 s$ and $16 s$ RNA (8; Rosemond and Sreevalsan,
Abstr. Annu. Meeting A.S.M., p. 242, 1972). These RNA species should be capable of coding for proteins with molecular weights of approximately $240,000,180,000$, and 70,000 . All large ts-11 polypeptides are too large to be translated from the 16s RNA. However, the 133,000dalton protein seems too small to represent the entire polypeptide product of the 26s RNA, unless there is a large segment which remains untranslated. In addition, even though both membrane proteins are glycosylated (21), the 133,000 -dalton protein seems too small to contain the amino acid sequence for two membrane proteins with molecular weights of about 53,000 , a capsid protein with a molecular weight of 30,000 , and at least two enzymes involved in RNA synthesis. Thus, the possibility remains that a larger precursor will yet be discovered. Analysis of tryptic peptides could reveal whether the large precursors of $t s-11$ and the capsid- mutants are identical, whether they are overlapping portions of a still larger precursor, or whether they are derived from different precursors. Similar studies could indicate whether the smaller proteins in $t s$-11-infected cells arise by cleavage of the largest or have unrelated amino acid sequences.

\section{ACKNOWLEDGMENTS}

I thank Elmer R. Pfefferkorn for advice and encouragement and for critically reading an earlier version of this manuscript.

This investigation was supported by Public Health Service research grant AI 08238 from the National Institute of Allergy and Infectious Diseases and a postdoctoral fellowship from The Anna Fuller Fund.

\section{LITERATURE CITED}

1. Baltimore, D. 1971. Polio is not dead. Perspect. Virol. 7:1-12.

2. Burge, B. W., and E. R. Pfefferkorn. 1966. Isolation and characterization of conditional-lethal mutants of Sindbis virus. Virology 30:204-213.

3. Burge, B. W., and E. R. Pfefferkorn. 1966. Complementation between temperature-sensitive mutants of Sindbis virus. Virology 30:214-233.

4. Burge, B. W., and E. R. Pfefferkorn. 1968. Functional defects of temperature-sensitive mutants of Sindbis virus. J. Mol. Biol. 35:193-205.

5. Burrel, C. J., E. M. Martin, and P. D. Cooper. 1970. Post-translational cleavage of virus polypeptides in arbovirus infected cells. J. Gen. Virol. 6:319-323.

6. Chance, R. E., R. M. Ellis, and W. W. Bromer. 1968. Porcine proinsulin: characterization and amino acid sequence. Science 157:697-700.

7. Dubos, P., and P. Faulkner. 1970. Molecular weights of Sindbis virus ribonucleic acid as determined by polyacrylamide gel electrophoresis. J. Virol. 6:145-147.

8. Eaton, B. T., T. P. Donaghue, and P. Faulkner. 1972. Presence of poly(A) in the polyribosome-associated RNA of Sindbis-infected BHK cells. Nature N. Biol. 238:109-111.

9. Friedman, R. M. 1969. Primary gene products of an arbovirus. Biochem. Biophys. Res. Commun. 37:369-373.

10. Jacobson, M. F., J. Asso, and D. Baltimore. 1970. 
Further evidence on the formation of poliovirus proteins. Proc. Nat. Acad. Sci. U.S.A. 61:77-84.

11. Kennedy, S. I. T. 1972. Isolation and identification of the virus-specified RNA species found on the membrane-bound polysomes of chick embryo cells infected with Semliki Forest virus. Biochem. Biophys. Res. Commun. 48:1254-1258.

12. Kiehn, E. D., and J. J. Holland. 1970. Synthesis and cleavage of enterovirus polypeptides in mammalian cells. J. Virol. 5:358-369.

13. Levin, J., and R. M. Friedman. 1971. Analysis of arbovirus ribonucleic acid forms by polyacrylamide gel electrophoresis. J. Virol. 7:504-514.

14. Loening, U. E. 1968. Molecular weights of ribosomal RNA in relation to evolution. J. Mol. Biol. 38:355365.

15. Marcus, P. I., and H. L. Zuckerbraun. 1970. Viral polymerase proteins as antiviral agents (intrinsic interference). Ann. N.Y. Acad. Sci. 173:185-198.

16. Pfefferkorn, E. R., and M. K. Boyle. 1972. Selective inhibition of the synthesis of Sindbis virion proteins by an inhibitor of chymotrypsin. J. Virol. 9:187-188.

17. Pfefferkorn, E. R., and B. W. Burge. 1967. Genetics and biochemistry of arbovirus temperature-sensitive mutants, p. 403-426. In J. S. Colter and W. Parenchych (ed.), The molecular biology of viruses. Academic Press Inc., New York.

18. Scheele, C. M., and E. R. Pfefferkorn. 1969. Kinetics of incorporation of structural proteins into Sindbis virions. J. Virol. 3:369-375
19. Scheele, C. M., and E. R. Pfefferkorn. 1969. Inhibition of interjacent ribonucleic acid (26s) synthesis in cells infected by Sindbis virus. J. Virol. 4:117-122.

20. Scheele, C. M., and E. R. Pfefferkorn. 1970. Virusspecific proteins synthesized in cells infected with $\mathrm{RNA}^{+}$temperature-sensitive mutants of Sindbis virus. J. Virol. 5:329-337.

21. Schlesinger, M. J., S. Schlesinger, and B. W. Burge. 1972. Identification of a second glycoprotein in Sindbis virus. Virology 47:539-541.

22. Shapiro, A. L., E. Vinuela, and J. V. Maizel, Jr. 1967. Molecular weight estimation of polypeptide chains by electrophoresis in SDS-polyacrylamide gels. Biochem. Biophys. Res. Commun. 28:815-820.

23. Strauss, J. N., Jr., B. W. Burge, and J. E. Darnell. 1969. Sindbis virus infection of chick and hamster cells: synthesis of virus-specific proteins. Virology 37:367-376.

24. Strauss, J. N., Jr., B. W. Burge, E. R. Pfefferkorn, and J. E. Darnell. 1968. Identification of the membrane protein and "core" protein of Sindbis virus. Proc. Nat. Acad. Sci. U.S.A. 59:533-537.

25. Waite, M. R. F., and E. R. Pfefferkorn. 1970. Phospholipid synthesis in Sindbis virus-infected cells. J. Virol 6:637-643.

26. Weber, K., and M. Osborn. 1969. The reliability of molecular weight determinations by dodecylsulfate-polyacrylamide gel electrophoresis. J. Biol. Chem. 244: 4406-4412. 